\title{
Characterization of untreated and neutralized bauxite residue for improved waste management
}

\author{
C.M. Carter \\ H.A. van der Sloot \\ D. Cooling \\ A. van Zomeren \\ T. Matheson
}

Published in Environmental Engineering Science, Volume 25, Number 4, 2008 


\title{
Characterization of Untreated and Neutralized Bauxite Residue for Improved Waste Management
}

\author{
Chanelle M. Carter, ${ }^{1,}{ }^{*}$ Hans A. van der Sloot, ${ }^{2}$ David Cooling, ${ }^{1}$ André van Zomeren, ${ }^{2}$ \\ and Tina Matheson ${ }^{1}$ \\ 'Technology Delivery Group \\ Alcoa World Alumina \\ Kwinana, Western Australia 6167 \\ ${ }^{2} \mathrm{ECN}$ \\ Environmental Risk Assessment \\ Department Clean Fossil Fuels \\ 1755 ZG Petten, The Netherlands
}

\begin{abstract}
Alumina refineries generate large volumes of bauxite residue daily, and as such, the storage, treatment, and reuse practices for residue are receiving increasing attention as refineries strive to reduce the potential environmental impact of their operations. To improve management decisions in the selection of appropriate storage, treatment, and reuse practices, the leaching behavior of bauxite residue was characterized using a standardized $\mathrm{pH}$ dependence leaching test. Leaching data was modeled using a geochemical speciation program to determine which chemical processes are controlling bauxite residue leaching behavior. This approach showed that the nine residue samples examined behaved very similarly for most elements, despite being generated by different refineries that utilize bauxite from different sources. Geochemical modeling of the leach data helped identify the solubility controlling minerals and other release controlling factors, which proved mostly the same for this wide range of samples. Residue treatments such as carbonation and seawater neutralization did affect the leaching of some elements, resulting in a change in the leaching behavior of the treated material compared with the untreated sample. Using geochemical speciation modeling, the changes were largely explained; hence, this approach, aimed at understanding the geochemical phases controlling release, provides a sound basis for waste management decisions in a wide range of storage and reuse scenarios.
\end{abstract}

Key words: bauxite residue; geochemical modeling; leaching; solubility; adsorption; waste management; treatment processes

\section{INTRODUCTION}

A LUMINA REFINERIES PROCESS BAUXITE, an aluminiumrich ore, to produce alumina, a purified aluminium oxide that is the precursor to aluminium metal. Alumina re- fineries use the Bayer process to produce alumina, in which bauxite is digested in hot sodium hydroxide (between 110 and $270^{\circ} \mathrm{C}$ ) to dissolve the aluminium minerals. The insoluble solid components, known collectively as bauxite residue (or red mud), are removed from the process, washed,

\footnotetext{
*Corresponding author: Technology Delivery Group, Alcoa World Alumina, P.O. Box 161 Kwinana, Western Australia 6167. Phone.
} +61 894103804 ; Fax: +61 89410 3197; E-mail: chanelle.carter@alcoa.com.au 
and deposited in residue storage areas. Bauxite residue can vary considerably in composition due to the variability in the natural ores used. Production of 1 tonne of aluminium (or 2 tonnes of alumina) produces between 1.5 and 4 tonnes of bauxite residue (on a dry weight basis). The bauxite residue is highly alkaline, with a $\mathrm{pH}$ generally greater than 11 , and is composed predominantly of iron, titanium and silicon oxides, calcium carbonate, and calcium aluminates, and desilication product (DSP), a sodium aluminosilicate mineral (Aluminium Association, 2000).

As alumina refineries strive to become more sustainable and environmentally accountable, it is inevitable that bauxite residue management practices will continue to improve. New approaches to residue management, such as residue neutralization and reuse of residue, are increasingly being investigated as ways to lessen the potential environmental impact of refinery operations. Whether residue is left in residue storage areas or exposed to different environments through reuse opportunities, understanding residue behavior has become critical in evaluating the potential impacts associated with the alternative methods for managing residue.

More specifically, Alcoa World Alumina has a corporate goal to reduce the amount of residue going to storage areas. Residue characterization is an integral part of meeting this goal; understanding the fundamental chemistry of residue material was seen as an essential prerequisite for investigating various reuse opportunities. Further, neutralization options such as carbonation and seawater neutralization have been investigated for reducing alkalinity of the residue material. Through extended research at Alcoa, residue carbonation was found to be extremely beneficial and will be installed at Alcoa's Kwinana refinery by 2007. Understanding the changes this will have on the fundamental properties of the residue will continue to be an important consideration as reuse options for this carbonated residue are explored.

In the past, leaching tests such as the Toxicity Characteristic Leaching Protocol (TCLP, 1990), and the Australian Standard Leaching Protocol (ASLP) test (Standards Australia, 1997) have been used to evaluate wastes for their potential to release trace elements. These tests are limited in their usefulness, as they provide leaching data at a limited number of $\mathrm{pH}$ values, and do not provide information about the long-term behavior of the sample (van der Sloot, 1996). The TCLP and ASLP leaching tests do not generate data that can be used to predict the leaching behavior of the sample in an environment that differs in $\mathrm{pH}$ and $\mathrm{Eh}$ from that of the leaching test. Moreover, the chemical processes that determine the leaching behavior are unknown. Single-point extraction tests using acetic acid as the eluate (similar to the ASLP and TCLP) and other extraction solutions have been shown to have a leaching behavior that is dependent on the $\mathrm{pH}$ of the extraction, and independent of the extraction solution (with the exception of the complexation agent EDTA); in other words, these data fall on the curve of the $\mathrm{pH}$ leach test when displayed as extracted amount versus $\mathrm{pH}$ (van der Sloot, 2002).

A new scenario approach to characterization of leaching behavior was jointly developed by the Energy Research Centre of The Netherlands (ECN) and Vanderbilt University (Nashville, TN) (Kosson et al., 2002), and has been applied to various bauxite residue samples. This technique involves characterizing bauxite residue leaching behavior using standardized $\mathrm{pH}$ dependence leaching tests over a $\mathrm{pH}$ range from $4-12$, and a standardized percolation leaching test. The data is subsequently analyzed using geochemical speciation models to determine which processes are controlling leaching. This approach has also been used successfully for a range of contaminated soils (Dijkstra et al., 2004).

The advantages of the scenario approach are many. Not only does it provide a basis for comparison for international leaching tests (such as the TCLP and the ASLP), but it provides the information required to perform geochemical modeling. This, in turn, allows the factors that control release to be identified, such as interaction with organic carbon, iron oxide surfaces, or clay, or control by minerals or redox condition. The $\mathrm{pH}$ dependence test will also provide acid (and base) neutralization capacity information, and information on $\mathrm{pH}$ conditions imposed by external influences (such as carbonation or imposed neutralization). It is applicable to almost any material, and also allows vastly different materials to be compared on the basis of their leaching behavior; similarities can exist in the mechanisms controlling leaching that would not be anticipated through their composition or through other leach tests. By contrast, the TCLP and ASLP only provide the information required to assess the material against regulatory criteria.

The purpose of the current work is to assess the leaching behavior of bauxite residue, without treatment, and after imposed carbonation and seawater neutralization, and to understand the underlying chemical processes that determine leaching behavior in each of these materials. This information can then be used as part of the assessment of seawater neutralization and carbonation, and to assess various reuse options. Leach tests performed at a single $\mathrm{pH}$ value, such as TCLP and the Italian leaching test for waste reuse evaluation, have been applied to untreated and treated residue in the past (Brunori et al., 2005), but these tests were performed for determining compliance with regulatory criteria. Leach data of this type cannot be used for understanding the mechanisms controlling leaching behavior. The current work is the first time that bauxite residue has been characterized by $\mathrm{pH}$ leaching tests and subsequently by geochemical modeling. This will enable a better understanding of the environmental impact of bauxite residue and might facilitate the development of improved utilization and disposal scenarios. 


\section{EXPERIMENTAL}

\section{Materials}

Bauxite residue slurry samples (super thickener underflow or last washer underflow) were collected from each of Alcoa's nine alumina refineries and filtered (glass microfiber filters, grade GF/B) to provide a consolidated sample with similar moisture content to residue in a storage area (approximately $70 \%$ solids by weight). The filtrate was retained as the porewater sample. Sea water neutralized residue slurry was prepared by mixing the unfiltered underflow sample ( 2.0 to $3.2 \mathrm{~kg}$ ) with seawater (approximately $60 \mathrm{~kg}$ ) for $48 \mathrm{~h}$. After this time the sample was allowed to settle overnight, the supernatant solution decanted, and the neutralized residue filtered to provide a wet residue cake. The supernatant solution was retained as the porewater sample. After neutralization, the samples were stored at room temperature in closed containers for periods of 2 weeks to 2.5 months prior to testing. Carbonated residue slurry was prepared by sparging unfiltered residue slurry with liquid food grade carbon dioxide $(>99.8 \%)$, until the $\mathrm{pH}$ reached either 9.0 (Australian residue) or 10.5 (all other residue samples). The samples were left over night, and where the $\mathrm{pH}$ had rebounded the samples were again sparged with carbon dioxide until the desired $\mathrm{pH}$ had been obtained. After carbonation, the residue samples were stored at room temperature in closed containers for periods of 11 days to 2 months prior to testing. Filtration of the carbonated samples was not required, because the carbonation resulted in the desired percent solids, so the porewater sample was collected by filtering a subsample of the carbonated residue (glass microfiber filters, grade GF/B). All residue samples satisfied the required grain size of $95 \%$ less than $1 \mathrm{~mm}$.

\section{Leaching test method}

The filtered residue samples were subjected to a $\mathrm{pH}$-dependent leaching test as described in CEN standard CEN/TS 14429 (2005). CEN/TS 14429 involves leaching the sample (at $20^{\circ} \mathrm{C}$, with a mixing rate at approximately $10 \mathrm{rpm}$ ) over a $\mathrm{pH}$ range of 4 to 12 (including the sample's natural $\mathrm{pH}$ ), for a period of $48 \mathrm{~h}$. Untreated residue samples were leach tested over the $\mathrm{pH}$ range of 0.5 to 12 .

The leaching test was performed at a liquid to solid (L/S) ratio of $10(\mathrm{~L} / \mathrm{kg}$ dry weight). Eight eluate solutions were prepared using $15.6 \mathrm{M}$ nitric acid and/or $2 \mathrm{M}$ sodium hydroxide. The mass of sample required (to give $15 \pm 1.5 \mathrm{~g}$ dry weight) was weighed into $250 \mathrm{~mL}$ polypropylene (PP) bottles, and one-third of the eluate solution added. The solution was equilibrated for $30 \mathrm{~min}$ in a rotating water bath $\left(20^{\circ} \mathrm{C}, 10 \mathrm{rpm}\right)$, before the next third of the eluate solution was added. The solution was equilibrated for another $90 \mathrm{~min}$ before the last portion of eluate was added. The sample was then allowed to equilibrate under continuous rotation for a further $44 \mathrm{~h}$. The solution $\mathrm{pH}$ was measured 4,44 , and 48 $\mathrm{h}$ after the initial eluate addition.

At the end of the 48-h equilibration period the bottles were centrifuged and then filtered through a $0.45-\mu \mathrm{m}$ membrane filter. The sample $\mathrm{pH}$ at 44 and $48 \mathrm{~h}$ did not vary by more than $0.3 \mathrm{pH}$ units for any sample, satisfying the condition for approaching equilibrium. The filtered eluate solutions and the entrained pore water of the sample collected prior to leach testing were analyzed for total organic carbon (TOC) by an O.I. Analytical Model 1010 Wet Oxidation TOC analyzer, chloride was determined colorimetrically, fluoride by ion specific electrode measurement and a range of major, minor, and trace elements were determined by Inductively Coupled Plasma (ICP) Mass Spectrometry, or by Inductively Coupled Plasma (ICP) Optical Emission Spectrometry. One residue sample was also leach tested according to a $\mathrm{pH}$ static approach, which is described in Meima and Comans (1997). This test is similar to that described above, except that the $\mathrm{pH}$ is continuously monitored and maintained at a predetermined $\mathrm{pH}$.

\section{Solids analysis}

All residue samples were analyzed for their total carbon content (by total combustion analysis), and for the total organic carbon content (by acidifying the samples to remove carbonate and analysing the residual carbon by total combustion analysis). The carbonate concentration was calculated as the difference between the total and organic carbon content. These concentrations were used to estimate the total carbonate concentration that was available for leaching, because this parameter is required for the geochemical modeling.

Untreated residue samples from Refinery 2 and Refinery 6 were analyzed for their clay content (i.e., content of material with particle size $<2 \mu \mathrm{m}$ ). This was done according to the standard NEN 5753 (2005). The samples were treated with hydrogen peroxide to oxidize the organic material, then with hydrochloric acid to remove carbonates, before the sample was dried and passed through a $35-\mu \mathrm{m}$ sieve. The $<35-\mu \mathrm{m}$ particles were separated by a settling experiment, and several time and depth fractions were collected to enable the mass percentage to be calculated according to Stokes Law, and hence, the clay content to be determined.

The reactive iron and aluminium content of the same two residue samples were determined by a series of extraction experiments. An ascorbate extraction (room temperature, 24 $\mathrm{h}, \mathrm{L} / \mathrm{S} 20$ ) was used to extract the amorphous iron oxides and hydroxides, a dithionate extraction $\left(60^{\circ} \mathrm{C}, 4 \mathrm{~h}, \mathrm{~L} / \mathrm{S} 20\right)$ was used to extract the amorphous and crystalline iron oxides and hydroxides, and an oxalate extraction (room temperature, $4 \mathrm{~h}, \mathrm{~L} / \mathrm{S} 100$ ) was used to extract the amorphous 
aluminium oxides and hydroxides. The iron extraction methods are described in Kostka and Luther (1994), and the aluminium extraction method in Blakemore et al. (1987).

The iron and aluminium oxides and hydroxides (IAH) were used to calculate the active surfaces available for adsorption reactions. The amorphous aluminium surfaces were considered to be important, and in the modeling the surrogate $\mathrm{FeOOH}$ was used for all IAH species. The site densities of amorphous aluminium and iron hydr(oxides) were calculated assuming a specific surface area of $600 \mathrm{~m}^{2} / \mathrm{g}$ (Dzombak and Morel, 1990), the same as that of FeOOH, while the crystalline iron hydr(oxide) was calculated assuming a specific surface area of $100 \mathrm{~m}^{2} / \mathrm{g}$ (Hiemstra et al., 1989). All concentrations were converted to $\mathrm{kg} / \mathrm{kg} \mathrm{FeOOH}$, taking into account the site densities of the different reactants. For a more detailed description of this approach, see Dijkstra et al. (2004, 2006).

Finally, the solid humic and fulvic acid content of these samples was determined, which was assumed to account for the reactive solid phase organic material. The samples were analyzed using a batch method based on the method of Swift (1996), and described in detail by van Zomeren and Comans (2007). The samples were extracted at $\mathrm{pH} \mathrm{1,} \mathrm{to} \mathrm{hydrogen}$ saturate the organic material and to remove multivalent cations, before the supernatant liquid was removed. The supernatant liquid from the acid treatment was treated with a DAX-8 resin to absorb the fulvic acids, and the organics remaining in solution after resin addition were classified as hydrophilic organic material. The solid material was treated to $\mathrm{pH} 12$ to maximize humic substances dissolution, and then reacidified to $\mathrm{pH} 1$ to reprecipitate the humic acids. The supernatant solution was treated with a DAX-8 resin to absorb the fulvic acids, leaving the hydrophilic material in solution. The DOC concentration was measured after every step. The total concentration of humic and fulvic acids, and hydrophilic organic materials, could then be calculated. The humic and fulvic acids were combined in the modeling as the active organic component, while it was assumed that the hydrophilic material was not reactive towards metal complexation. The reactive component of the dissolved organic carbon in the eluate solutions (i.e., humic and fulvic acids) was assumed to be $20 \%$.

\section{Geochemical modeling}

Modeling was carried out on all treated and untreated residue samples to predict leaching of all elements, and to identify the solubility controlling processes. The recently developed JAVA-based modeling tool ORCHESTRA (Meeussen, 2003) was used as chemical speciation code. Partitioning between free ion and complexed metal species in solution as well as element partitioning in the solid phase was assessed. The model approach is based on a combination of a number of recently developed mechanistic adsorption and speciation models. Solution speciation was calcu- lated using thermodynamic data from the MINTEQA2 (Allison et al., 1991) database, version 3.11, with some modifications (see Dijkstra et al., 2002, for a description of these changes). Additional minerals that were relevant to seawater neutralized systems were also included in the database (Lothenbach and Winnefeld, 2005). The Davies equation was used to calculate species activities. The NICA-Donnan approach was used for adsorption to organic matter (Kinniburgh et al., 1999), and it uses the recently published generic parameters for proton (Milne et al., 2001) and metal complexation (Milne et al., 2003). Using the measured DOC and POM as input, these models (as embedded in ORCHESTRA) then calculate competition between free metal ion concentrations and available specific sorption sites on dissolved and particulate organic matter based on the binding constants. These parameters were derived for natural soil and aquatic humic acids, but the modeling outcomes indicate that they might also be valid for residue humic acids. The Diffuse Layer model of Dzombak and Morel was used for adsorption to hydrous ferric oxides (Dzombak and Morel, 1990). A Donnan model was used to calculate adsorption to permanently charged clay surfaces, assuming a charge density of 0.25 equiv $/ \mathrm{kg}$ and a fixed Donnan volume of $1 \mathrm{~L} / \mathrm{kg}$. The interface used between these models was the Leaching Expert System (LeachXS) version 1.0.4.1 (van der Sloot et al., 2003). The input parameters used for untreated residue from Refinery 2 and Refinery 8 are given in Table 1 ; these reflect bauxite residue from widely different geographical locations, and also provide solid surface values that were measured (Refinery 2) and estimated for modeling purposes (Refinery 8 ).

\section{RESULTS AND DISCUSSION}

\section{Acid neutralization capacity $(A N C)$}

The amount of added acid/base and the final $\mathrm{pH}$ of each eluate solution (generated according to CEN/TS 14429, 2005) can be used to generate the acid neutralization capacity (ANC) curve of the material tested. The acid/base addition is calculated as $\mathrm{mol} \mathrm{H}^{+} / \mathrm{kg}$ (dry weight sample), with base addition expressed as a negative value.

The ANC of the residue samples vary considerably, depending not only on the type of treatment they have received, but also on the refinery in which the residue was generated (Fig. 1). Neutralization reduces the native $\mathrm{pH}$ of the material, and decreases the material's ANC. ANC behavior is likely to be dependent on the refinery operating conditions, particularly in regard to residue washing and causticization efficiency (the causticization process reacts lime with sodium carbonate in the refinery liquor to regenerate sodium hydroxide; calcium carbonate is produced as a byproduct and will report to residue). Seawater neutralization, in particular, and carbonation of residue decrease the variability 
Table 1. Parameters used for geochemical modeling for untreated bauxite residue from Refinery 2 and Refinery 8 .

\begin{tabular}{|c|c|c|c|c|c|}
\hline \multirow[b]{2}{*}{ Reactant } & \multicolumn{2}{|c|}{ Available concentration $(\mathrm{mg} / \mathrm{kg})$} & \multirow[b]{2}{*}{ Reactant } & \multicolumn{2}{|c|}{ Available concentration $(\mathrm{mg} / \mathrm{kg})$} \\
\hline & Refinery 2 & Refinery 8 & & Refinery 2 & Refinery 8 \\
\hline $\mathrm{Ag}^{+}$ & 0.11 & 0.11 & $\mathrm{Mg}^{+2}$ & 2,000 & 180 \\
\hline $\mathrm{Al}^{+3}$ & 30,000 & 74,000 & $\mathrm{Mn}^{+2}$ & 3.6 & 5.6 \\
\hline $\mathrm{H}_{3} \mathrm{AsO}_{4}$ & 13 & 7.5 & $\mathrm{MoO}_{4}^{-2}$ & 5.5 & 17 \\
\hline $\mathrm{H}_{3} \mathrm{BO}_{3}$ & 6.7 & 9.0 & $\mathrm{Na}^{+}$ & 37,000 & 90,000 \\
\hline $\mathrm{Ba}^{+2}$ & 12 & 45 & $\mathrm{Ni}^{+2}$ & 1.0 & 7.3 \\
\hline $\mathrm{Ca}^{+2}$ & 43,000 & 38,000 & $\mathrm{PO}_{4}^{-3}$ & 380 & 600 \\
\hline $\mathrm{Cd}^{+2}$ & 0.28 & 0.28 & $\mathrm{~Pb}^{+2}$ & 11 & 51 \\
\hline $\mathrm{Cl}^{-}$ & 1,200 & 2,800 & $\mathrm{SO}_{4}^{-2}$ & 2,400 & 4,300 \\
\hline $\mathrm{H}_{2} \mathrm{CO}_{3}{ }^{\mathrm{a}}$ & 50,000 & 48,000 & $\mathrm{Sb}[\mathrm{OH}]_{6}^{-}$ & 0.056 & 0.23 \\
\hline $\mathrm{CrO}_{4}^{-2}$ & 12 & 50 & $\mathrm{SeO}_{4}^{-2}$ & 3.0 & 2.8 \\
\hline $\mathrm{Cu}^{+2}$ & 4.4 & 5.3 & $\mathrm{H}_{4} \mathrm{SiO}_{4}$ & 20,000 & 66,000 \\
\hline $\mathrm{F}^{-}$ & 400 & 40 & $\mathrm{Sr}^{+2}$ & 260 & 250 \\
\hline $\mathrm{Fe}^{+3}$ & 720 & 770 & $\mathrm{Th}^{+4}$ & 28 & 31 \\
\hline $\mathrm{Hg}^{+2}$ & 0.056 & 0.70 & $\mathrm{UO}_{2}{ }^{2+}$ & 15 & 3.9 \\
\hline $\mathrm{K}^{+}$ & 72 & 550 & $\mathrm{VO}_{2}^{+}$ & 190 & 280 \\
\hline $\mathrm{Li}^{+}$ & 1.1 & 3.4 & $\mathrm{Zn}^{+2}$ & 1.1 & 6.8 \\
\hline
\end{tabular}

The minerals beta-tricalcium phosphate (except Refinery 2 seawater neutralized residue), calcite, ferrihydrite, fluorite, tricalcium aluminate hexahydrate $\left(3 \mathrm{CaO} \cdot \mathrm{Al}_{2} \mathrm{O}_{3} \cdot 6 \mathrm{H}_{2} \mathrm{O}\right)$ for untreated samples and tricalcium aluminate monocarbonate $\left(3 \mathrm{CaO} \cdot \mathrm{Al}_{2} \mathrm{O}_{3} \cdot \mathrm{CaCO}_{3}\right.$. $\left.11 \mathrm{H}_{2} \mathrm{O}\right)$ for neutralized residue samples, hydrotalcite $\left(\mathrm{Mg}_{4} \mathrm{Al}_{2}(\mathrm{OH})_{14} \cdot 3 \mathrm{H}_{2} \mathrm{O}\right.$ for seawater neutralized residue samples and $\mathrm{Mg}_{4} \mathrm{Al}_{2}(\mathrm{OH})_{12} \cdot \mathrm{CO}_{3} \cdot 2 \mathrm{H}_{2} \mathrm{O}$ for untreated and carbonated residue) and gibbsite (or diaspore in the case of Refinery 1 seawater neutralized residue) were used in the modeling for all untreated and neutralized residues. In addition, the minerals analcime, $\mathrm{FeCr}_{2} \mathrm{O}_{4}$, $\mathrm{Ba}[\mathrm{SCr}] \mathrm{O}_{4}\left[96 \% \mathrm{SO}_{4}\right], \mathrm{MnHPO}_{4}$, and $\mathrm{PbMoO}_{4}$ were used in the modeling of Refinery 8 untreated residue, and analcime, $\mathrm{FeCr}_{2} \mathrm{O}_{4}$, barite, $\mathrm{BaCaSO}_{4}[50 \% \mathrm{Ba}]$, and $\mathrm{PbMoO}_{4}$ were used to model Refinery 2 untreated residue. All untreated and carbonated residue samples were modeled using $\mathrm{pH}+\mathrm{pe}=12$, while seawater neutralized residue used $\mathrm{pH}+\mathrm{pe}=14$. The parameters used for the solid surfaces were: Refinery 2: clay $-0.38 \mathrm{~kg} / \mathrm{kg}, \mathrm{HFO}-0.12 \mathrm{~kg} / \mathrm{kg}$, SHA -0.0053 , and Refinery $8:$ clay-0.30 kg/kg, HFO—0.10 kg/kg, SHA-0.004 .

aThese values were estimated based on modeling outcomes, and measured total carbonate concentrations of 54,000 and $62,000 \mathrm{mg} / \mathrm{kg}$ respectively.

in $\mathrm{ANC}$ at $\mathrm{pH}>6$. ANC can be used in scenario descriptions for estimation of long-term leaching behavior.

\section{Leaching tests}

The $\mathrm{pH}$ dependent leaching of aluminium and calcium is shown in Fig. 2. Aluminium leaching from residue varied over four orders of magnitude in the $\mathrm{pH}$ range 4 to 12 . Clearly, $\mathrm{pH}$ was a major factor in determining aluminium leaching from residue, a point that would not be obvious from the regulatory ASLP or TCLP tests. The leaching behavior was very similar for each untreated residue sample tested, indicating that the chemical processes controlling leaching were the same.

Residue carbonation did not significantly change the leaching behavior of aluminium compared with untreated residue (Fig. 2). However, seawater neutralization of residue decreased the amount of aluminium leached from residue at $\mathrm{pH}>9$; this change was independent of the $\mathrm{pH}$ change that occurred due to neutralization.

Residue neutralization by carbonation did not seem to affect the leaching of most elements; the leaching of many el- ements was below detection limits, making it difficult to assess the impact of neutralization on these species. Calcium leaching was reduced in all carbonated residue samples; this change was independent of the imposed $\mathrm{pH}$ change due to neutralization (Fig. 2). Carbonation increased phosphorus and fluoride leaching, and in some residues iron and titanium leaching, in the alkaline $\mathrm{pH}$ range. Fluoride leaching at the natural $\mathrm{pH}$ of the carbonated sample, however, was lower than fluoride leaching at the natural $\mathrm{pH}$ of the untreated residue.

Seawater neutralization affected leaching behavior predominantly by changing the concentration of species available for leaching; for highly soluble species such as Mo, seawater neutralization washed out a proportion of the component, leading to a lower concentration leaching. For other components that were present in high concentrations in seawater, such as $\mathrm{Cl}, \mathrm{B}, \mathrm{Mg}$, and $\mathrm{K}$, the addition of seawater to residue increased the available concentrations of these elements, leading to higher concentrations leaching from seawater neutralized residue compared with untreated residue. In the case of $\mathrm{K}$ and $\mathrm{Cl}$, this could be directly related to porewater replacement by seawater. The change in the con- 


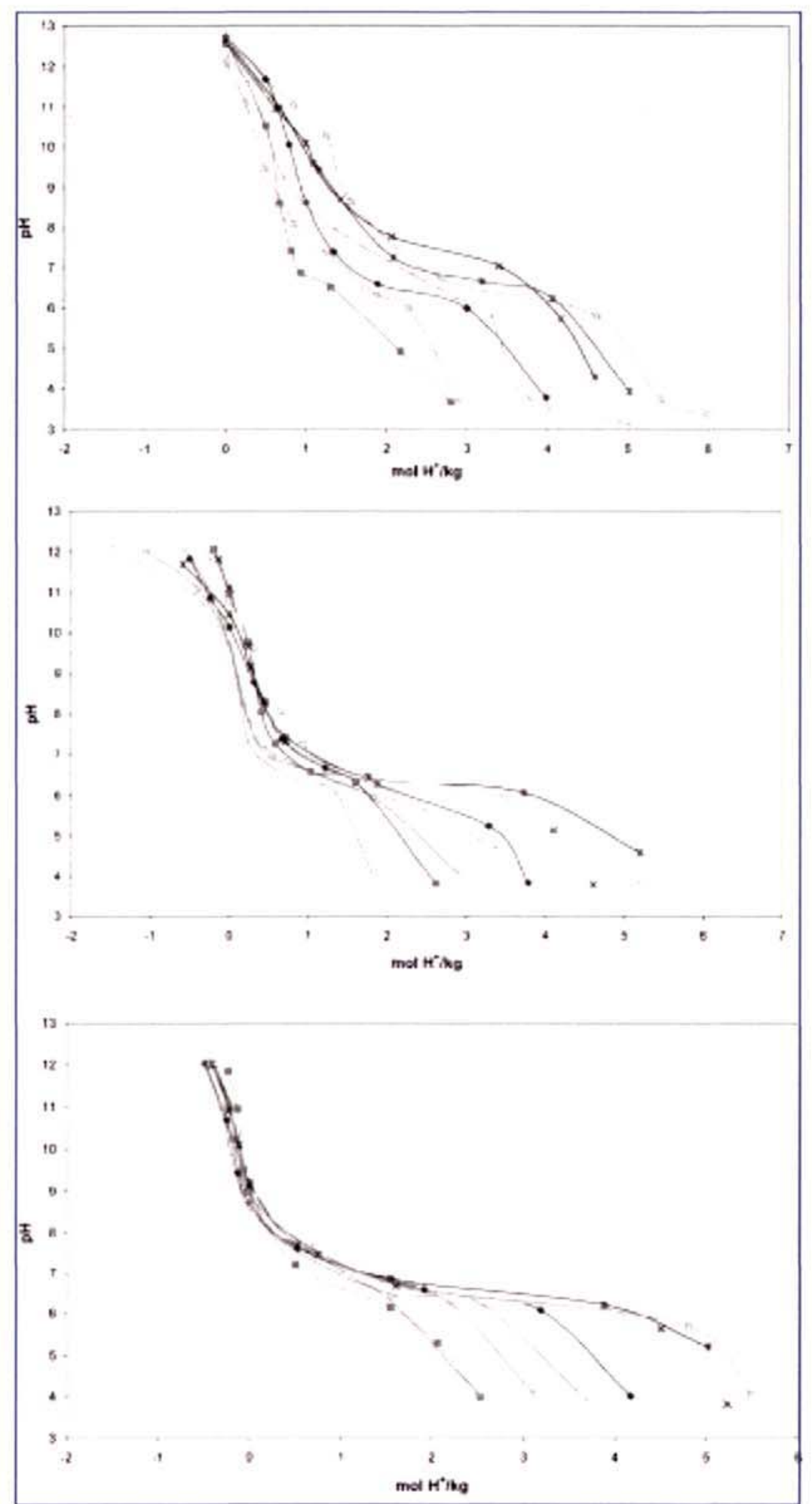

Figure 1. Acid neutralization capacity (ANC) curves for untreated residue samples (top), carbonated residue samples (middle), and seawater neutralized residue samples (bottom). Each refinery is shown with the same symbol in the three charts. 


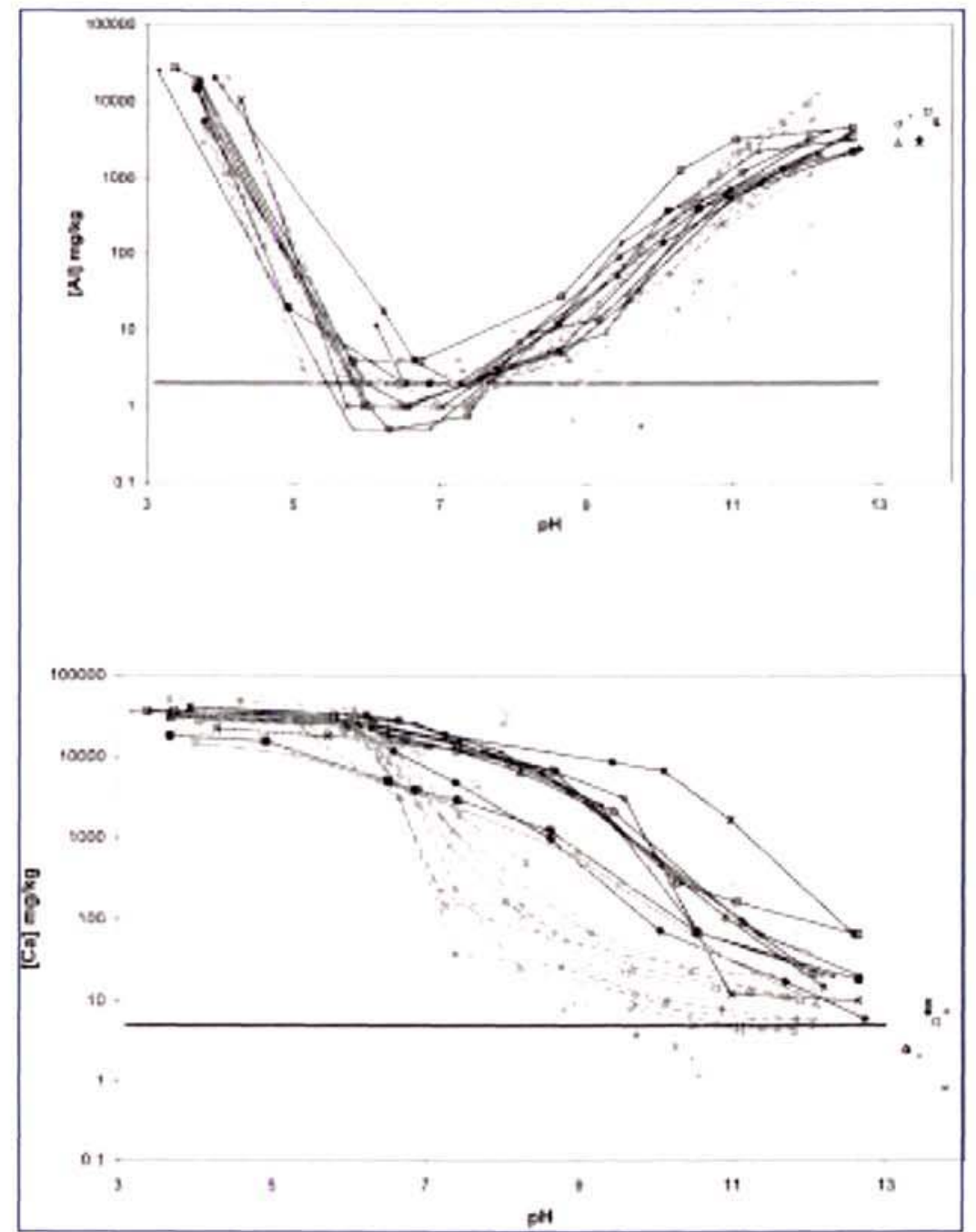

Figure 2. Aluminium and calcium leaching from untreated residue samples (black lines), carbonated residue samples (gray dashed lines) and seawater neutralized residue samples (pale gray dotted lines) as a function of $\mathrm{pH}$. Isolated symbols are porewater samples, and the horizontal line shows the detection limit. The different symbols correspond to the different refineries, and is consistent across all three treatments.

centration of species available for leaching in seawater neutralized residue could not explain the change in leaching behavior for all elements. For example, it could not account for the decreased $\mathrm{Al}$ and $\mathrm{Ga}$ leaching and increased $\mathrm{F}$ leaching in the alkaline $\mathrm{pH}$ range. As with carbonated residue, fluoride leaching at the natural $\mathrm{pH}$ of the seawater neutralized residue was lower than fluoride leaching at the natural $\mathrm{pH}$ of the untreated residue.

For most elements, neutralization leads to a decrease in leaching when comparing untreated and neutralized residues at their natural $\mathrm{pH}$. Exceptions include $\mathrm{Ca}$ and $\mathrm{Mg}$, which are more soluble at neutral compared to alkaline $\mathrm{pH}$, as well as $\mathrm{B}, \mathrm{Cl}$, and $\mathrm{K}$ leaching from seawater neutralized residue as was described previously.

\section{Partition modeling}

Geochemical speciation modeling using element availabilities, quantities of iron and aluminium (hydr)oxide (IAH) phases, organic matter in solid and liquid, and selected minerals provides a prediction of release for all elements in comparison with the actually measured $\mathrm{pH}$ dependence leaching test data. The degrees of freedom to vary any one parameter are limited, as many elements are interrelated and 
an improvement in the modeling of one element may deteriorate the match for other elements. The parameters that were modified to improve residue modeling included the mineral selection, and the available carbonate concentration (ensuring that this value was less than or equal to the measured total carbonate concentration). Solid surface parameters (particularly the IAH and active organic material) were optimized when modeling residue for which these parameters had not been measured, although the final values were within the range measured for Refinery 2 and Refinery 6 residue. When the model predictions closely match the data, the chemical processes that determine the leaching behavior are understood and the partitioning of elements between solid and liquid phases can be assessed. The good agree-

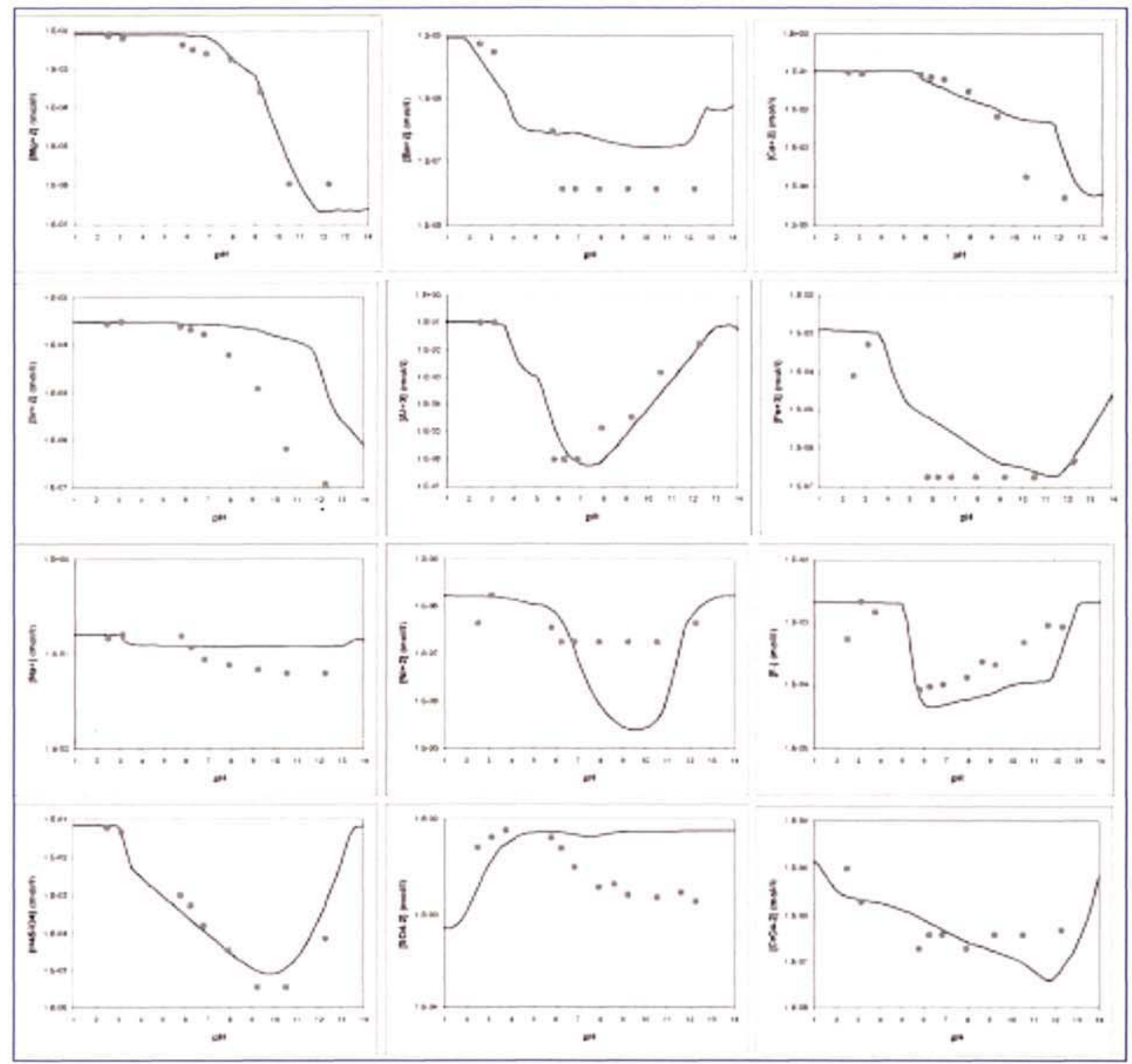

Figure 3. Model prediction (line) versus actual leaching behavior (dots) for Refinery 2 bauxite residue, for the elements: $\mathrm{Mg}, \mathrm{Ba}, \mathrm{Ca}$, $\mathrm{Sr}, \mathrm{Al}, \mathrm{Fe}, \mathrm{Na}, \mathrm{Ni}, \mathrm{F}, \mathrm{Si}, \mathrm{SO}_{4}{ }^{2-}$ and $\mathrm{CrO}_{4}{ }^{2-}$. Note that for $\mathrm{Mg}, \mathrm{Ba}, \mathrm{Fe}$, and $\mathrm{Ni}$, the lowest eluate concentrations are at the analytical detection limit. The elements $\mathrm{Pb}, \mathrm{P}, \mathrm{As}, \mathrm{Se}, \mathrm{Sb}, \mathrm{Th}$, and $\mathrm{Cd}$ are not shown because the leaching was mostly at or below the analytical detection limits (similar to the data shown for $\mathrm{Zn}, \mathrm{Fe}$, and $\mathrm{Ba}$ ), while $\mathrm{Cu}, \mathrm{Mn}$, and $\mathrm{Zn}$ are shown in other figures. The controlling phases for the elements $\mathrm{Mo}, \mathrm{V}$, and $\mathrm{U}$ have not been identified, and the elements $\mathrm{K}$ and $\mathrm{Cl}$ showed similar leaching behavior (and modeling predictions) to $\mathrm{Na}$. 
ment between the actual and predicted leaching of 12 elements from untreated residue from Refinery 2 is shown in Fig. 3; in total, 27 elements were simultaneously predicted.

The modeling as performed allows the quantification of element partitioning between dissolved (free plus inorganic and DOC bound) and particulate species (bound to iron and aluminium (hydr)oxide, minerals, and particulate organic matter). This type of partitioning will prove to be highly informative for material modification, bioavailability, and judgement of transport because DOC bound elements are carried further into the soil groundwater system than free elements (McCarthy and Zachara, 1989). Free elements will bind to iron and aluminium (hydr)oxides, clay or solid organic matter, limiting their transport through the soil profile. Specific mineral phases have been identified as controlling release (see Table 1). The adsorption processes and minerals used to model solubility were very consistent between residue samples, despite the wide variation in geo- graphical location for the bauxite source and residue production. For all residue samples, a sodium aluminosilicate mineral such as analcime, analbite or albite, was used to model silicon solubility. These minerals are most likely surrogates for the Bayer specific mineral referred to as desilication product, which is a sodium aluminosilicate with a composition similar to sodalite (Lowe et al., 2005). Magnesium leaching in seawater neutralized samples was best modeled using the hydrotalcite mineral with the chemical composition $\mathrm{Mg}_{4} \mathrm{Al}_{2}(\mathrm{OH})_{14} \cdot 3 \mathrm{H}_{2} \mathrm{O}$, as opposed to $\mathrm{Mg}_{4} \mathrm{Al}_{2}$ $(\mathrm{OH})_{12} \cdot \mathrm{CO}_{3} \cdot 2 \mathrm{H}_{2} \mathrm{O}$ for the untreated and carbonated residue, and aluminium solubility seemed to be controlled by a different mineral in the seawater neutralized residue samples compared with the untreated and carbonated residue samples; otherwise, the major solubility controlling minerals used for modeling untreated and neutralized residue were the same. These solubility controlling processes are discussed further in the following sections.
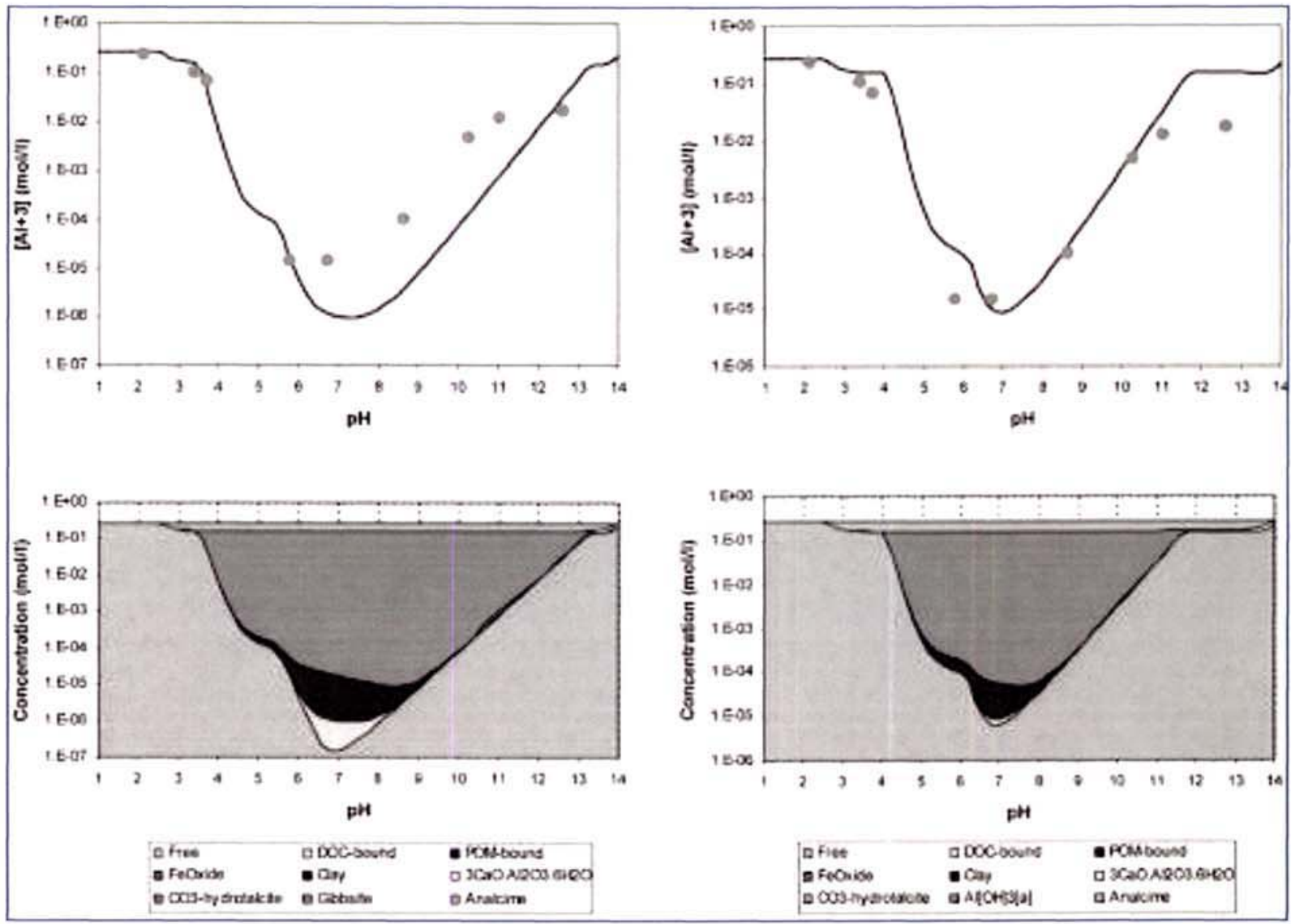

Figure 4. Solubility and partitioning prediction for aluminium in bauxite residue from Refinery 8 using gibbsite (left) and amorphous alumina (right) as the controlling mineral phases. The top charts show measured aluminium concentration (dots) compared with the model predictions (line). 
Solid surface analysis. Untreated residue samples from Refinery 2 and Refinery 6 were analyzed for their solids content for input into the geochemical speciation modeling. The residue samples were found to have very high clay contents, 38 and $29 \%$, respectively. A value of $30 \%$ clay was used in the modeling for the residue samples for which a clay analysis had not been undertaken; varying the clay content between 30 and $40 \%$ had very little impact on the modeling outcomes. For example, chloride, the element most affected by the clay content of residue, changed by less than $3 \%$ in solution when the clay concentration of Refinery 8 residue was changed from 30 to $40 \%$ in the modeling.

The iron and aluminium (hydr)oxide (IAH) content, converted to $\mathrm{kg} / \mathrm{kg} \mathrm{FeOOH}$, was found to be 11.9 and $8.0 \%$, respectively, with more than $85 \%$ of the active surface contribution being from amorphous aluminium species. The rest of the IAH contribution was from crystalline iron species; amorphous iron content was negligible $(<0.15 \%$ of the total reactive IAH content). An IAH concentration of $10 \%$ was used in the modeling of residue samples for which no analysis was performed; this value was then optimized to improve the modeling outcome.

The active organic content of the residue samples is calculated as the sum of the humic and fulvic acid content. The active organic content of the two residue samples varied quite considerably, with the measured concentrations being 5,300 and $400 \mathrm{mg} / \mathrm{kg}$, respectively. This variation is in part due to the different organic content of the source bauxites and in part due to the residue sample from Refinery 2 being collected after less intensive (process) washing than the Refinery 6 sample. Hence, DOC concentration in the entrained process liquor will be more highly concentrated in the more poorly washed sample. Nonetheless, this analysis provides an indication of the order of magnitude over which the active organic content of the residue samples may range, which is useful for modeling these and other bauxite residue samples. The measured values were used for modeling Refinery 2 and 6 residues, while values within this concentration range were used for other refinery residue samples, and modified to optimize the modeling.

Aluminium. The minerals that gave the best solubility predictions for aluminium were gibbsite, boehmite, and anhydrous alumina. The solubility product of gibbsite and boehmite are very similar, although boehmite is slightly less soluble than gibbsite, so on the basis of giving better solubility predictions these minerals cannot be separated. However, because gibbsite is more soluble than boehmite, gibbsite is more likely to be the solubility controlling mineral. Boehmite and gibbsite are both present in bauxite residue (Brunori et al., 2005).

When amorphous aluminium hydroxide is used in the modeling to predict aluminium solubility, the solubility of aluminium in the alkaline region is predicted well. However, aluminium solubility at the sample's natural $\mathrm{pH}$ (approximately 12.5 ) and in acidic conditions is better predicted when gibbsite is used as the solubility controlling mineral phase (Fig. 4).

This discrepancy can be explained by kinetic processes. At the sample's natural $\mathrm{pH}$, the system is at (or close to) thermodynamic equilibrium and gibbsite is the solubility controlling phase. Once acid is added, aluminium hydroxide precipitation occurs. Although the crystalline form of aluminium hydroxide, gibbsite, is thermodynamically more stable, precipitation of the amorphous aluminium hydroxide occurs first. This is explained by the Ostwald Step Rule, which says that the more soluble and less stable phase is precipitated first, followed sequentially by increasingly less soluble but more stable phases; the kinetics of these mineral transformations will dictate the length of time required
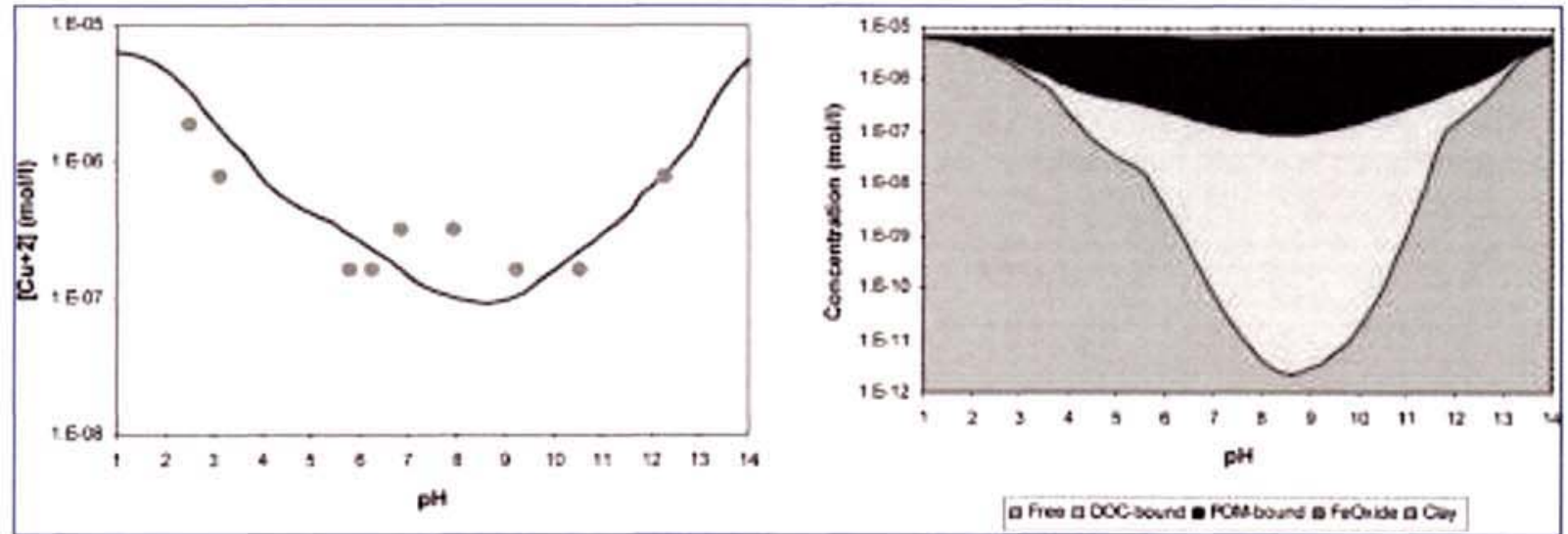

Figure 5. Solubility (left) and partitioning (right) prediction for copper in bauxite residue from Refinery 2. The solubility prediction chart shows measured copper concentration (dots) compared with the model predictions (line). 
to attain thermodynamic equilibrium (Steefel and van Capellen, 1990). As gibbsite precipitation is extremely slow, amorphous aluminium hydroxide best predicts aluminium solubility in the $\mathrm{pH}$ range where aluminium hydroxide is precipitating. As more acid is added, and the $\mathrm{pH}$ falls below 6, aluminium hydroxide dissolution occurs. Kinetically, gibbsite dissolution is a much faster process than gibbsite precipitation, and hence, aluminium solubility under acidic conditions is predicted well when gibbsite is used in the modeling. Gibbsite, then, is expected to be the thermodynamically stable solubility controlling phase for aluminium leaching, and for long-term modeling predictions gibbsite should be used.

The partitioning modeling indicates that adsorption to solid organic matter around $\mathrm{pH} \mathrm{6-9}$ is another factor controlling aluminium solubility, although is only a minor factor relative to the effect of gibbsite. The speciation of aluminium in solution is predicted to be an organic complex around neutral $\mathrm{pH}$; otherwise, it is present as a free or inorganic ion.
Calcium, fluoride, and phosphorus. Geochemical modeling on untreated residue samples lead to the conclusion that calcium solubility can be predicted assuming several minerals as solubility controlling phases. The most important mineral for controlling calcium solubility was calcite, $\mathrm{CaCO}_{3}$. Tricalcium aluminate hexahydrate $\left(3 \mathrm{CaO} \cdot \mathrm{Al}_{2} \mathrm{O}_{3}\right.$. $\left.6 \mathrm{H}_{2} \mathrm{O}\right)$ or tricalcium aluminate monocarbonate $(3 \mathrm{CaO}$. $\mathrm{Al}_{2} \mathrm{O}_{3} \cdot \mathrm{CaCO}_{3} \cdot 11 \mathrm{H}_{2} \mathrm{O}$ ), which are present in Bayer process solids (Taylor and Pearson, 2001) and cannot be distinguished by modeling, and tricalcium phosphate (TCP), $\mathrm{Ca}_{3} \mathrm{PO}_{4}$, were also relevant solubility controlling phases at high $\mathrm{pH}$. Fluorite, $\mathrm{CaF}_{2}$, was important in controlling the solubility of fluoride, even though its impact on calcium solubility was minimal.

These minerals also controlled calcium solubility in carbonated bauxite residue, even though calcium and fluoride leaching were both altered by the carbonation process. Modeling showed that the solubility of both fluoride and calcium were strongly influenced by the carbonate concentration. As the carbonate concentration increased, calcite precipitation

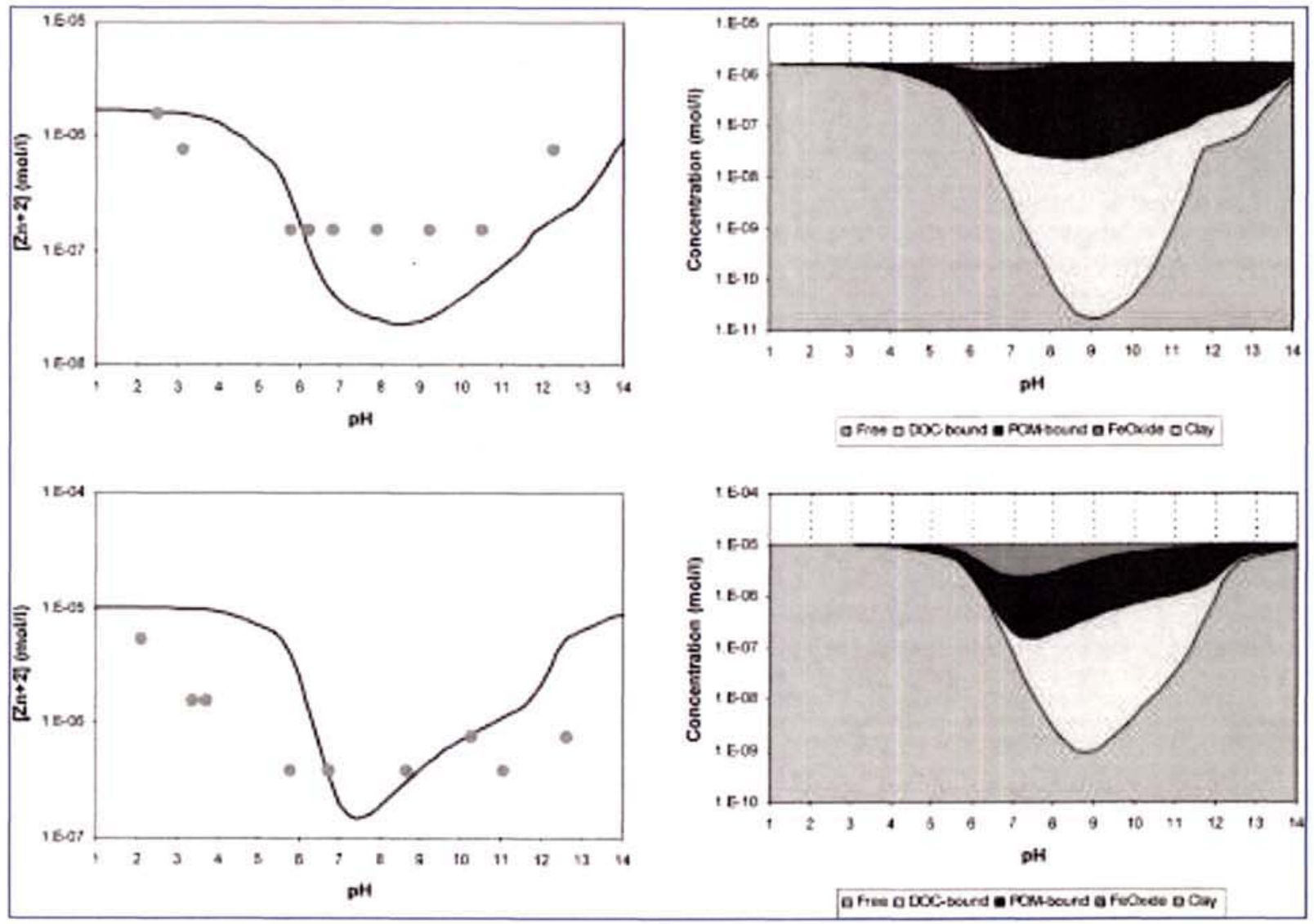

Figure 6. Solubility (left) and partitioning (right) prediction for zinc in bauxite residue from Refinery 2 (top) and Refinery 8 (bottom). The solubility prediction charts show measured zinc concentration (dots) compared with the model predictions (line); the detection limit for zinc was $1.5 \times 10^{-7} \mathrm{M}$ for Refinery 2 and $3.8 \times 10^{-7} \mathrm{M}$ for Refinery 8 . 
increased, resulting in the decrease in calcium leaching observed at $\mathrm{pH}>7$ (see Fig. 2). This is related to the Ksp of calcite: Ksp (calcite) $=\left[\mathrm{Ca}^{2+}\right]\left[\mathrm{CO}_{3}{ }^{2-}\right]$, so that when $\left[\mathrm{CO}_{3}{ }^{2-}\right]$ increases, the required $\left[\mathrm{Ca}^{2+}\right]$ for calcite precipitation will be lower.

This leads to a decrease in the solution calcium concentration in the $\mathrm{pH}$ range where calcite precipitates. Because the Ksp of fluorite is dependent on calcium concentration, that is, Ksp (fluorite) $=\left[\mathrm{Ca}^{2+}\right]\left[\mathrm{F}^{-}\right]^{2}$, then an increased concentration of fluoride is required (compared with the situation for noncarbonated residue) for fluorite precipitation to occur. This mechanism may also account for the increased fluoride solubility in seawater neutralized residue, because the total concentration of calcium available for leaching was decreased by the neutralization process.

Model calculations show that phosphorus solubility is controlled by the mineral tricalcium phosphate (TCP), $\mathrm{Ca}_{3} \mathrm{PO}_{4}$, at high $\mathrm{pH}$. By the same logic as applied previously, the reduction in calcium concentration at high $\mathrm{pH}$ in the carbonated systems means that an increased concentration of phosphate is required for calcium phosphate precipitation: Ksp (calcium phosphate) $=\left[\mathrm{Ca}^{2+}\right]^{3}\left[\mathrm{PO}_{4}{ }^{3-}\right]^{2}$. This mechanism accounts for the increased phosphorus concentration in high $\mathrm{pH}$ eluate solutions from nearly all carbonated residue compared with untreated residue.

Geochemical modeling provides a detailed understanding of the chemistry controlling element solubility, and as such methods to alter leaching can be formulated. For example, if fluoride leaching needed to be controlled at high $\mathrm{pH}$, then a reasonable prediction would be that calcium addition to residue would achieve this by allowing fluorite precipitation to occur at a lower fluoride concentration. Increasing the available calcium concentration in the modeling of carbon- ated residue samples confirms this expectation, and does predict reduced fluoride solubility in the alkaline $\mathrm{pH}$ range. While this example may not be practical, it serves to illustrate the advantage of better understanding the chemical processes that control residue leaching behavior.

Copper. Modeling showed that copper leaching from residue was not controlled by minerals, but rather by the distribution of active organic material in the solid and liquid phase. Copper leaching is predicted well by geochemical modeling, which predicts that copper is almost exclusively associated with solid organic material in the solid phase (Fig. $5)$. Even in solution, copper is present as an organic complex over a wide $\mathrm{pH}$ range, and only at very high and very low $\mathrm{pH}$ does free copper become significant. Zinc solubility is also controlled to a large extent by active organic species, although adsorption to iron and aluminium (hydr)oxides is also an important factor in controlling zinc leaching; the relative importance of these phases varies between residues (Fig. 6).

Understanding the mechanism controlling copper and zinc leaching provides the opportunity to manage their chemistry, if so desired. Reducing the concentration of soluble humic and fulvic acids would reduce copper and zinc leaching significantly. This is also true for other samples; removing DOC has been predicted to reduce copper leaching from municipal solid waste incinerator bottom ash samples by two and three orders of magnitude (Meima et al., 1999).

Manganese. Manganese solubility in residue was controlled predominantly by adsorption to iron and aluminium (hydr)oxides (IAH), with adsorption to POM a minor con-

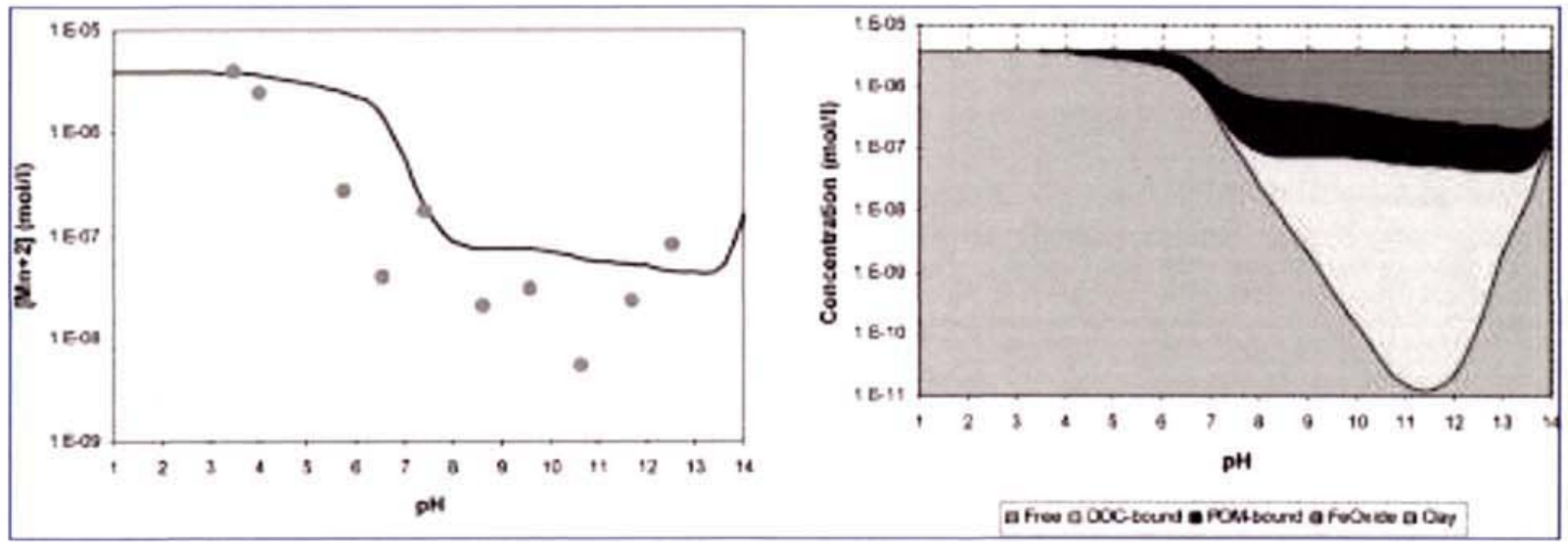

Figure 7. Solubility (left) and partitioning (right) prediction for manganese in bauxite residue from Refinery 2 . The solubility prediction chart shows measured manganese concentration (dots) compared with the model predictions (line). The data was generated using the $\mathrm{pH}$ static leach test (CEN TS14497) method; the ANC method provided the same modeling outcomes, but poorer detection limits meant that the accuracy of the modeling could not be validated. 
trolling factor (Fig. 7). The IAH in residue is predominantly amorphous aluminium species, and so factors that change the concentration of amorphous aluminium in residue will change the solubility of elements that are adsorbed to IAH. One factor that is likely to change the amorphous aluminium content of residue is aging; amorphous minerals will slowly crystallize over time to thermodynamically more stable forms, possibly reducing the surface area for adsorption.

The solubility of many elements were controlled by adsorption to IAH, including arsenic, antimony, and selenium, although the accuracy of the modeling could not be verified because the leaching of these components was at or below detection limits for most of the $\mathrm{pH}$ range. The retention of these species is often beneficial (due to their toxicity), and because of this the use of modified bauxite residue shows potential in the treatment of acid rock drainage (McConchie et al., 2005).

\section{CONCLUSIONS}

The application of the $\mathrm{pH}$ dependence test to bauxite residue provides a significantly increased understanding of bauxite residue leaching behavior. In combination with sophisticated geochemical modeling it allows a very advanced understanding of element partitioning between dissolved and particulate phases. In addition, it provides the means to describe leaching behavior under conditions deviating from those tested in the laboratory.

This approach showed that the contaminant releases from the nine residue samples examined are controlled by the same phases for most elements, despite being generated by different refineries that utilize bauxite from different sources. Gibbsite, calcite, fluorite, tricalcium phosphate, barite, ferrihydrite, hydrotalcite, tricalcium aluminate hexahydrate, and/or tricalcium aluminate monocarbonate, and a sodium aluminosilicate mineral, as well as the role of iron and aluminium (hydr)oxides, and organic matter (dissolved and particulate) were shown to be controlling the release behavior of a wide range of major, minor, and trace elements from untreated and neutralized bauxite residue. Apart from the increased understanding of solubility controlling processes, it immediately presents potential for durable improvement of residue quality.

Residue treatments such as carbonation and seawater neutralization did affect the leaching of some elements and left others virtually unaffected. Seawater neutralization washed out some highly soluble components, such as Mo, which led to reduced leaching, while it increased the concentration of other components such as $\mathrm{Cl}, \mathrm{B}, \mathrm{Mg}$, and $\mathrm{K}$, which led to increased leaching compared with untreated residue. In the case of $\mathrm{K}$ and $\mathrm{Cl}$, this could be directly related to porewater (entrained residue water) replacement by seawater. $\mathrm{Al}$, $\mathrm{Ga}$, and $\mathrm{F}$ leaching were also affected by seawater neutral- ization. Carbonation changed $\mathrm{Ca}, \mathrm{F}$, and $\mathrm{P}$ leaching in the alkaline $\mathrm{pH}$ range. The associated changes in controlling mineral solubility could be explained by the geochemical modeling.

This full mechanistic modeling approach provides the development of more durable solutions to residue management than single step tests ever can. Although utilization and storage scenarios based on the present full thermodynamic description of bauxite residue leaching are still to be done, the potential for predicting release with associated partitioning is a major step ahead in a more advanced environmental impact evaluation and selection of treatment processes.

\section{DISCLOSURE STATEMENT}

The authors declare there are no competing financial interests.

\section{REFERENCES}

ALLISON, J.D., BROWN, D.S., and NOVO-GRADAC, K.J. (1991). MINTEQA2/PRODEFA2, Geochemical Assessment Model for Environmental Systems: Version 3.1I Databases and Version 3.0 User's Manual. Athens, GA: Environmental Research Laboratory, US-EPA.

ALUMINIUM ASSOCIATION. (2000). "Technology Roadmap for Bauxite Residue Treatment and Utilization." Summary of workshop (Alcoa, Alcan, Kaiser, Energetics, The Aluminum Association, 2000, DBS\&A, University of California) prepared by Energetics Inc., http://www.aluminum.org/Content/NavigationMenu/The_Industry/Technology_Resources/Technology_Articles/bauxite.pdf. Accessed March, 2006.

BLAKEMORE, L.C., SEARLE, P.L., and DALY, B.K. (1987). Methods for chemical analysis of soils. Science Report 80 . Lower Hutt, New Zealand: NZ Soil Bureau.

BRUNORI, C., CREMISINI, C., MASSANISSO, P., PINTO, V. and TORRICELLI, L. (2005). Reuse of a treated red mud bauxite waste: Studies on environmental compatibility. J. Hazard. Mater. B117, 55.

CEN/TS 14429. (2005). Characterization of waste-Leaching behaviour tests - Influence of $\mathrm{pH}$ on leaching with initial acid/base addition.

DIJKSTRA, J.J., VAN DER SLOOT, H.A., and COMANS, R.N.J. (2002). Process identification and model development of contaminant transport in MSWI bottom ash. Waste Manage. 22, 531.

DIJKSTRA, J.J., MEEUSSEN, J.C.L., and COMANS, R.N.J. (2004). Leaching of heavy metals from contaminated soils: An experimental and modeling study. Environ. Sci. Technol. 38(15), 4390.

DIJKSTRA, J.J., VAN DER SLOOT, H.A., and COMANS, R.N.J. (2006). The leaching of major and trace elements from MSWI 